\title{
Housing Estates Information Management System Based on .NET
}

\author{
Jianliang Min \\ College of Information Engineering, Jiangxi University of Technology, Jiangxi Nanchang
}

Keywords: House resource management; Customer management; Housing estates information management; Visual Studio 2005

\begin{abstract}
In order to effectively and conveniently manage house information for the intermediary company, this paper designed and developed housing estates information management system. The system adopts the current popular programming software Microsoft Visual Studio 2005 as the foreground development tool. The function modules include: housing management, customer management, sales management, lease management, and statistical analysis, etc. It can provide users with sufficient information and quick inquiry method. The system completes the whole process of house information management by applying the principles of simple operation, friendly interface, flexible, practical and safe as the start.
\end{abstract}

\section{Introduction}

Housing intermediary is an important part of the housing estate industry. It plays an important role in the whole operation process of the housing estate industry economy and offers a variety of intermediary services of production, circulation and consumption. Housing intermediary institutions often have a lot of information to process. The traditional manual registration method for processing large amounts of information is not only low efficiency, but easy to make mistakes, sometimes even miss information, while the development of computer technology provides a good way to solve the problem.

Traditional manual registration of housing intermediary companies often has piles of files need to deal with. The process of record, update and query for housing information is very slow and making mistakes as well. The high quality of information service and meet customer demand quickly cannot be and guaranteed. As a result, time is wasted invisibly and time, manpower and material resources increase the operation cost of housing intermediary companies. So the development of housing intermediary management system has great significance to the housing intermediary personnel, as well as the customers. The system offers convenient housing information record, update, and query. Meet the requirement of customers timely, and improve working efficiency of the intermediary institutions. At the same time, for students majoring computer science and technology about to graduate, the development of such a set of management software is also a very meaningful activity to apply theory to practice.

\section{Requirement Analysis of System}

Present situation and existing problems. As an organization of house information management, the information of housing intermediary industry should be accurate and correct. 
Therefore, to improve the work efficiency of the intermediary company, the use of software engineering design and database to design housing intermediary management software is particularly important.

The development of "housing estate intermediary management system" positioning in a database management system, which possesses the basic function of a database management system, including the increase, delete, modify, query of the data and so on, makes it easy for users to view, operate, and query the housing register information. In addition, the system has login function of members and the administrator which can improve the safety and reliability of the data. The system meets the requirements of the housing estate intermediary companies. Following the principle of clear demand analysis, users' participation, optimization of innovation, high efficiency and standardization, makes the development model more perfect.

The feasibility analysis. The purpose of the feasibility study is not solving the problem, but to determine whether the problem is worth to solve. Feasibility study essentially is to conduct analysis system and design process which has greatly compressed and simplified. That is the process of a higher level to undertake analysis system and design process in a more abstract way. The feasibility analysis can be implemented from the following three aspects.

Technical feasibility:

Technical feasibility considers that whether the use of existing technical conditions can accomplish the development of the project, whether software and hardware configuration meet the needs of development, etc. The work of housing intermediary management system is mainly building a bridge between customers and housing intermediary personnel, which can provide information to each other as well as process information. This characteristic is very suitable for the characteristics of the computer and the rapid development of computer hardware and software technology provides the technical conditions for the construction of the system. Analyses on the working process of the housing intermediary, and .NET development platform offer reliable reference and basis for implementing experiment smoothly, of which is the convenience of database link and realized information management system which is applied to database knowledge.

Economic feasibility:

The relationship between development and maintenance costs and expected benefits of the system should be considered for economic feasibility. The system is suitable for small and medium-sized housing intermediary; the cost of the development of the system mainly includes the cost of the development phase and the operation, maintenance cost in the future. The benefits that the new system bring comes from the scientific, standardized and efficient wok of the housing intermediary institutions, which mainly reflected in reducing staff, improving work efficiency, reducing payrolls correspondingly, meeting customers' demand easier, expanding customer base of the housing intermediary company, and reducing losses by errors compared with the traditional way of manual registration.

Operational feasibility:

This system is suitable for Windows XP and other mainstream operating system, which provides a good way in promoting the use of this system. After researching the wok process of the housing intermediary company, and fully considering the work habits of personnel before, and to make it easier to adapt to the new system, the system mainly depends on using Windows operating technology to complete data input, modify, delete, and other functions, which is 
convenient and simple. The user only need simple description and read assistant files before using the system.

In addition, the clear interface is easy to understand, and combined with the visual management tools, the operation of the database is quite simple, so the operation is feasible.

Requirement analysis of the system function. The implementation of housing intermediary management system requires conforming to the actual situation; analyze the actual situation objectively and insight into the requirements. The demand of housing intermediary management system mainly includes information registration, query, modify and delete both of housing information and customers requires. Housing intermediary register the information and input the system, the storage information in the system can be read and modified timely. Normally, the ordinary staff can only browse and query the specific housing information, while the administrator user not only can query the housing information, but register housing information, release, modify and delete the data as well. Therefore, the limits of authority between ordinary users and administrator users must be clearly distinguished, to prevent data loss and data errors due to operation mistakes. Specific analysis is as follows:

Add operation: to check whether the data has been input before the operation. If the data is wrong or not completed; the system will remind you of the correct information. While if the data is correct, the information will be input and saved by clicking the add button.

Delete operation: to delete information after selection, which will be displayed in the front-end interface.

Query operation: query all the data as well as fuzzy query, which is "like" in SQL statements. Combination query is to determine the final form of SQL statements by estimating the input data of the users, such as the input query data is not completed, even only one data, the system also can query out the corresponding data.

\section{Database design}

The database concept structure can be converted to the actual data mode supported by Microsoft SQL Server 2005 system that is the logic structure of database. The database contains users' information table, role information table, the customer information table, housing information table, supporting facilities table, property category table, table, housing area to affiliated regional table and housing follow-up information table, etc.

Database concept structure design. According to the demand analysis, the entities include: housing information entities, customer information entities, signed information entities, contract entities, employee information entities, role information table and follow-up information table.

Every entity is the abstract of real objects. There may be some relationship between two or among more entities. The E-R diagram among entities is as shown in Fig. 1. 


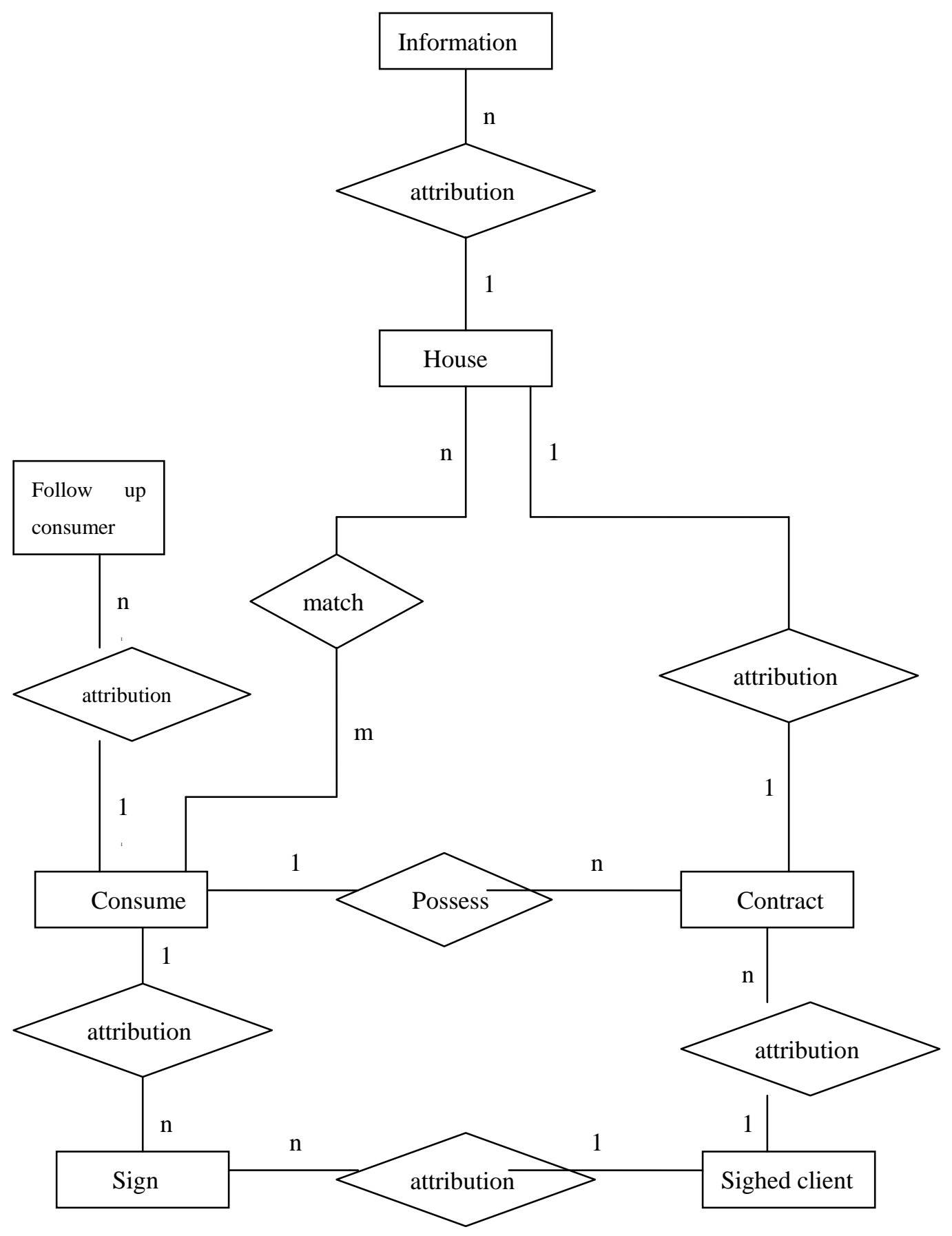

Fig. 1 The E-R diagram among entities

Individual entity Fig. 2 to 7 


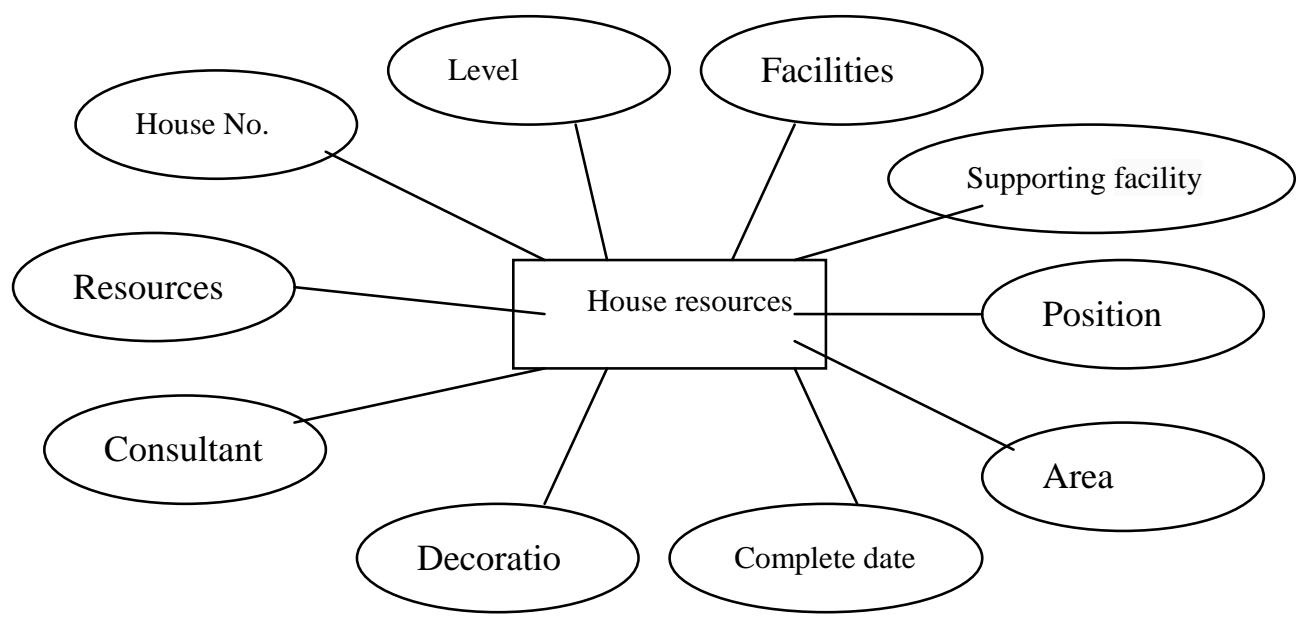

Fig. 2 House resources

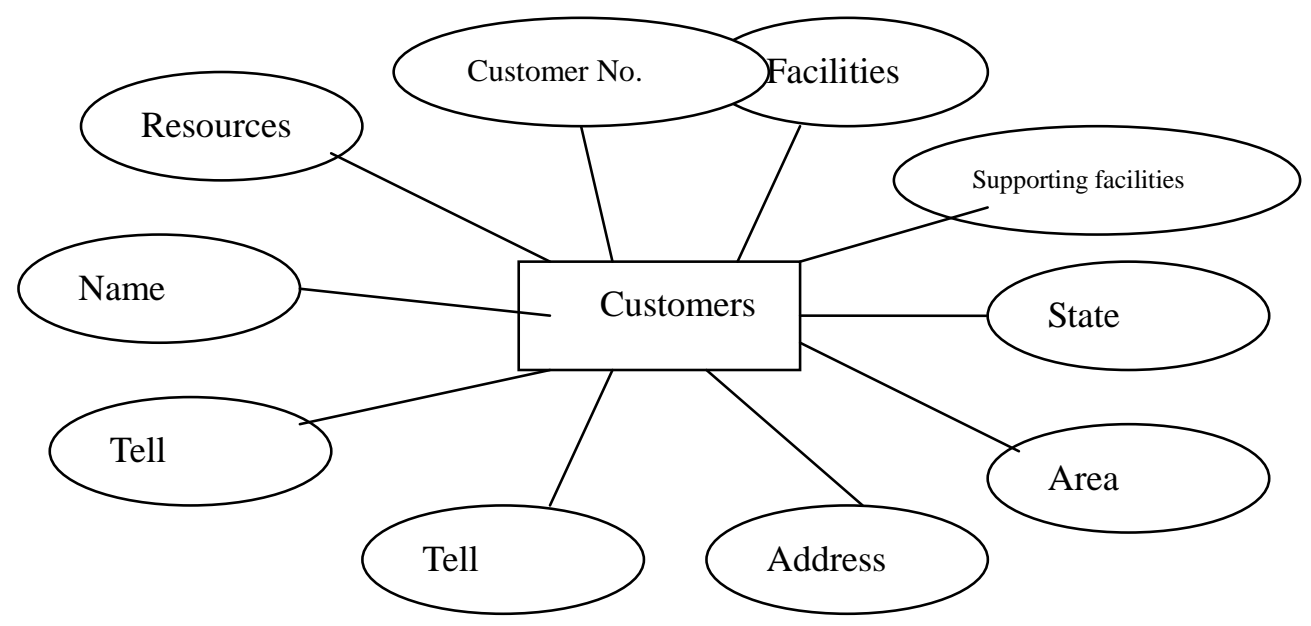

Fig. 3 Customers

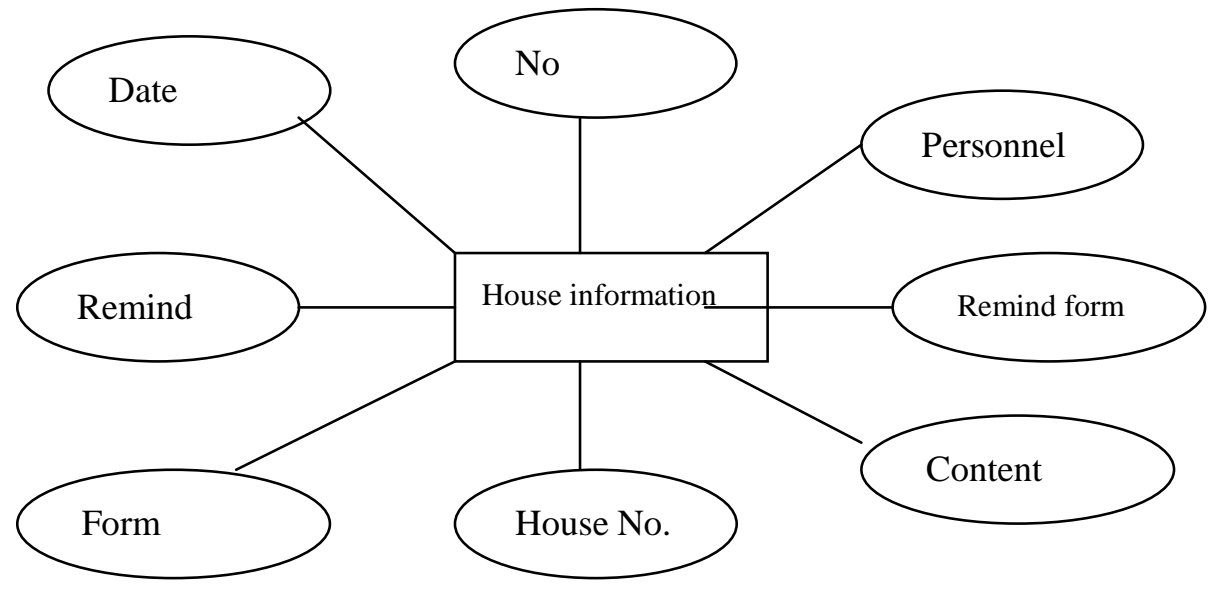

Fig. 4 House information follow up 


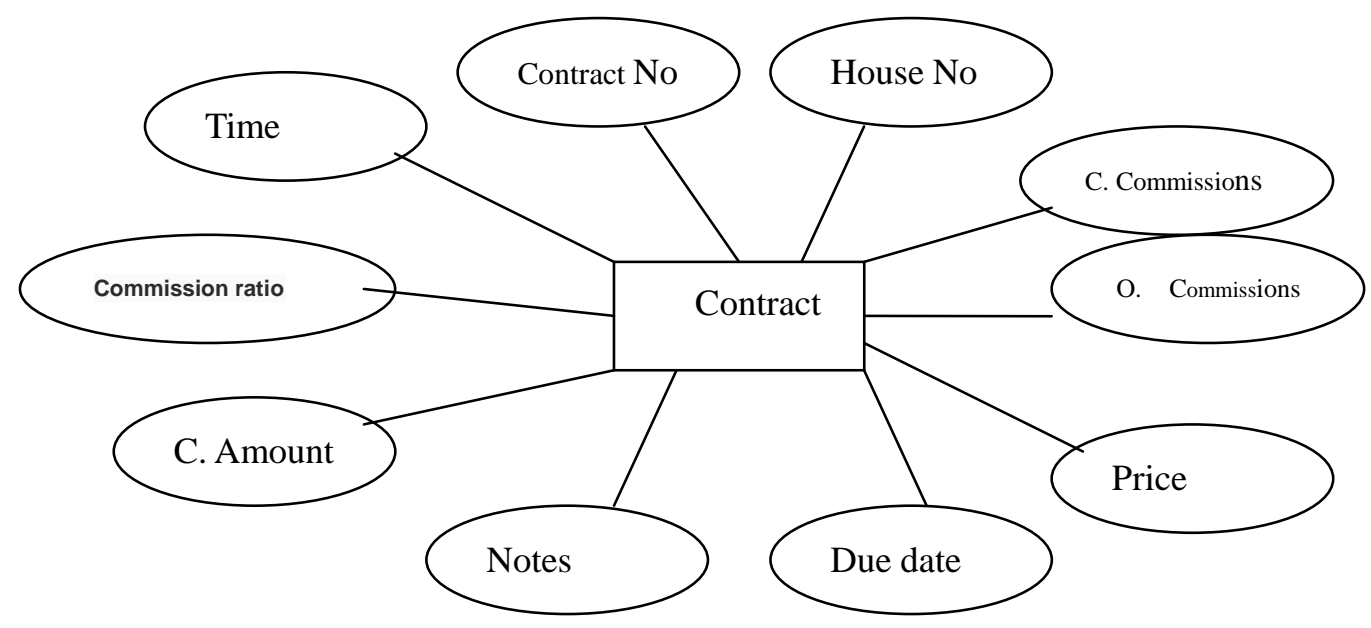

Fig. 5 Contract

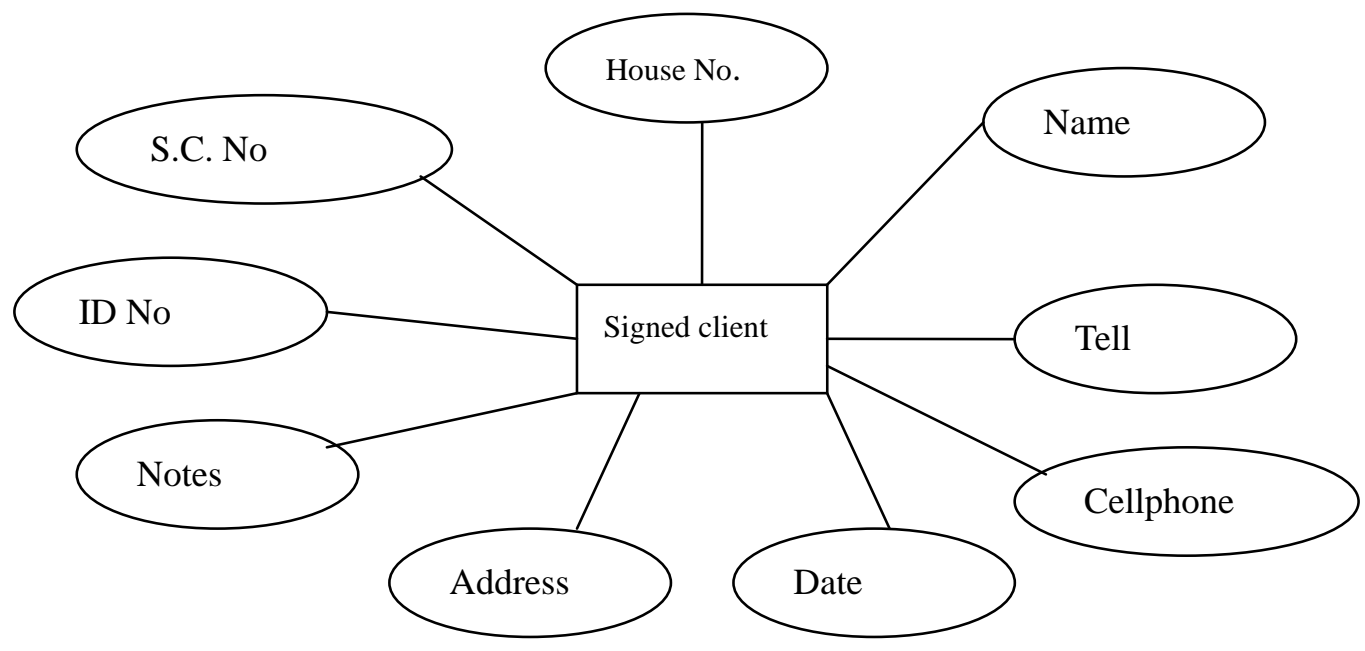

Fig. 6 Signed client

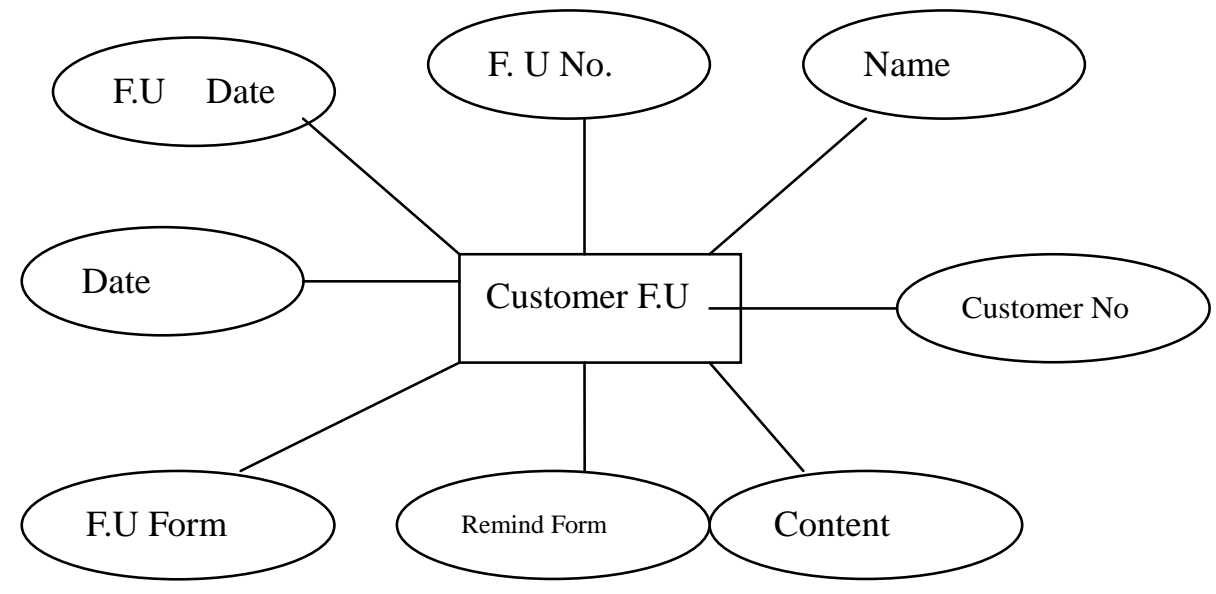

Fig. 7 Customers follow up information 
Database logical structure design. Logical structure design is as below:

Housing information (House No., current state, description of property, decoration, position region, address, area, facilities, location, layer, owner's name, room type, function of property company and Tell.) ;

Contract information (Contract No., House No., payment form, customers' commission, owners' commission, commission ratio, commission amount, due date and notes. ) ;

Customer information (customer No., customer name, customer source, property names, decoration, building types, specific address, the minimum value of construction area, the maximum value of construction area, minimum rents , maximum rents, rent instruction. );

Signed customers (customer No., house No., customer name, contact Tell, mobile phone, customer ID, customers' address and signing date.);

Housing follow-up information (follow up No., house No., follow up personnel, follow up form, follow up content, whether to remind, remind form);

Customer follow-up information (follow up No., house No, follow up personnel, follow up form, follow up content, date and remind form.);

\section{General design of system}

The function of each module of the system. Housing intermediary system plays a bridge role between the renter and rent seeker. It is mainly composed of customer information management, employee information management, housing management, common tools and system maintenance modules. The specific plan is as below:

Daily management

1. New houses: use as the circumstance of querying, modifying, signing a contract and matching houses, etc.

2. New customers: use as the circumstance of querying, modifying, signing a contract and matching customers, etc.

3. The query of follow up: follow up in later situation of querying to the registered houses and customers, through the query can help employees to track the dynamic of the clients to arrange work reasonably and timely.

4. Rent query: to check the qualified houses. The housing access speed and the accuracy of the requirements are greatly improved. As the mouse click to query a house, if there is suitable customer, all the houses conformed to the needs of customers will show at "automatic matching customer" at the lower right corner of the main window, which provides convenience for staff to offer quick and convenient services to the customers.

Daily management is mainly to provide convenient to the users, that is, provides fast operation in the main interface of the system.

Daily management flow is as fig. 8; 


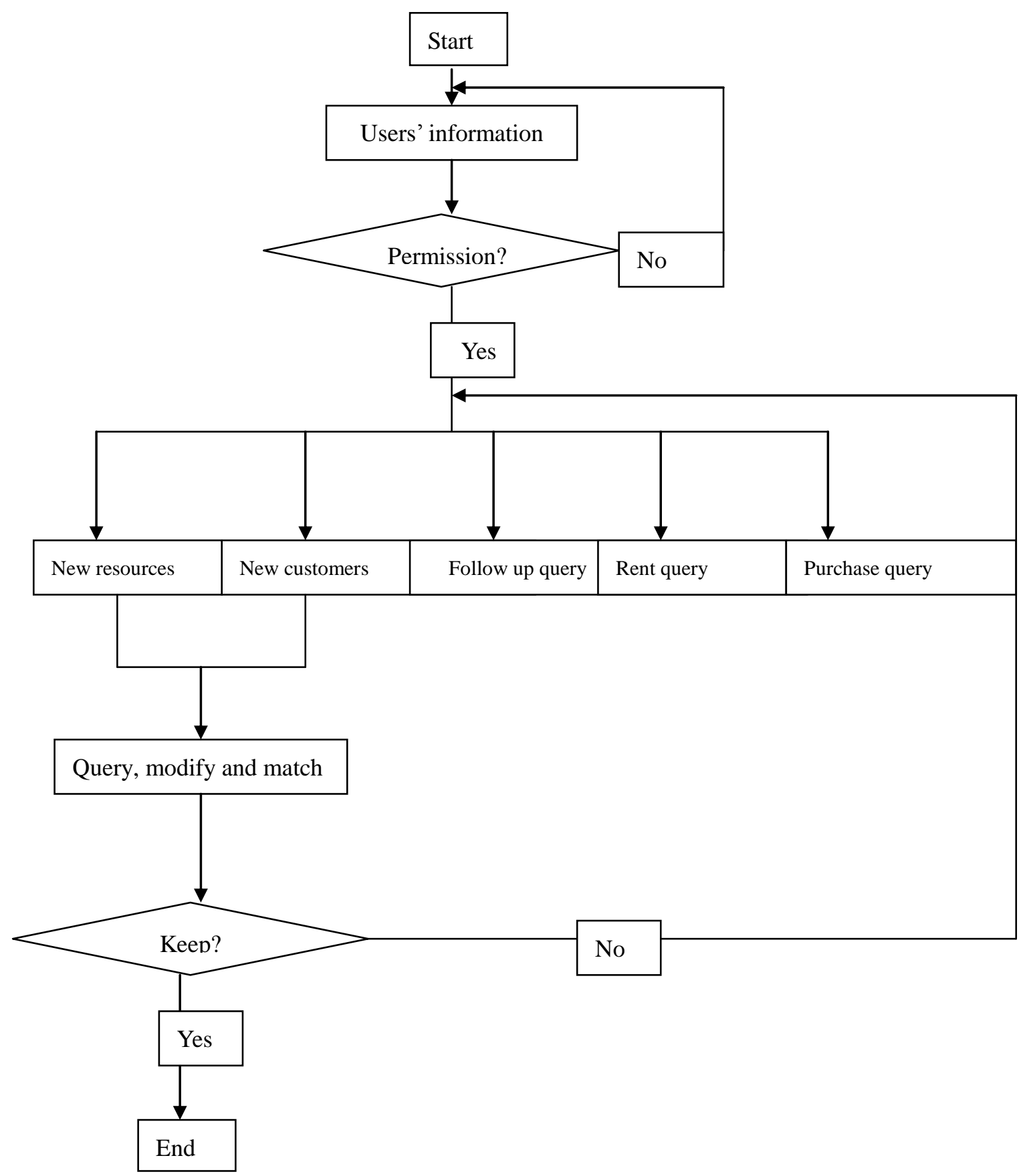

Fig. 8 Daily management flow

House resource management:

1. The house resource can be added, modified, deleted, queried, exported and printed etc. through housing management, meanwhile, each housing resource can match clients automatically. The way of adding house resource is same as the way in the "daily management". Clicking on a house in the housing management, the matched customers will show at "automatic matching customer" in the lower part of the window.

2. House resource follow-up: including the follow-up management and follow up the query two parts. Follow a house by querying the housing follow-up management, and add, delete and print the information at the bottom of the window after positioning properties. Search all the information about house resources by keyword in the query section. And master the progress of house resources and customers. 
3. Transaction management includes transaction management and transaction records two parts. The management part mainly completes the contract signing between property and customer. And the record part is used to query all details of transaction houses.

Sign: first search the house information in the transaction management, after confirming, the sign divides into two parts; signing contract registration and commission distribution. Select the customer type in the contract registration (if it is a registered customer, the customer information twill show as the customer number is input). Fill in the actual contract information; register allocation proportion to the staff that gets commission in the deal, so that the staff commission can be queried in the future.

Modification: if any error is found in the signed contract information, the information can be modified using this feature.

4. Store poster: mainly provides print function of poster, the houses in different parts or specific to a certain properties to print the posters. Posters include small poster and large poster. When it applied to batch poster or single poster, errors can be reduced in artificial posters and improve the working efficiency greatly.

Housing management is as Fig. 9 


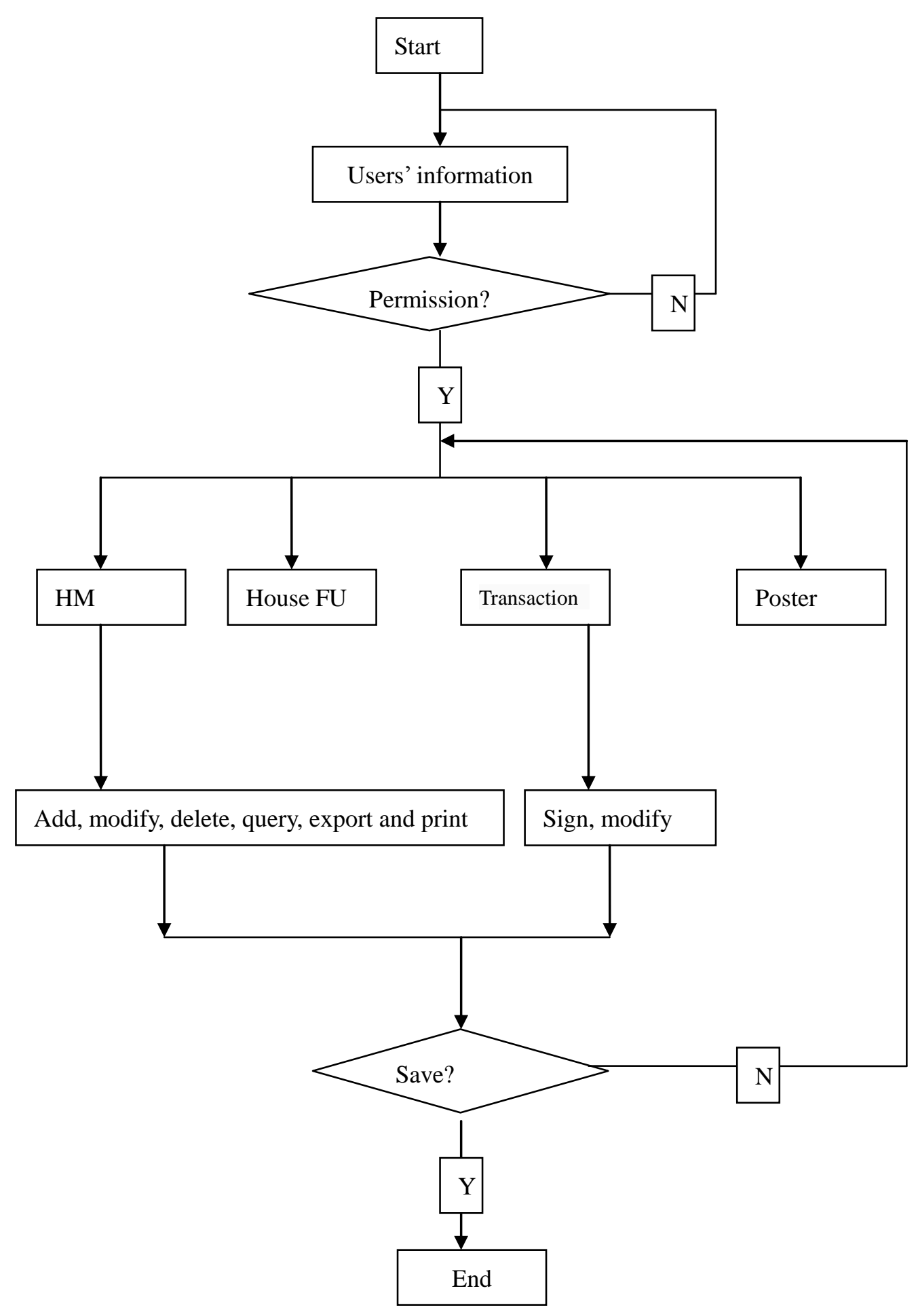

Fig. 9 Housing management

Customer's management:

Customer's management: the customers' information can be added, modified, queried, exported and printed etc as well as match house resource automatically.

Follow up customers: be divided into two parts of following up management and following up query. 
Sign query: all the sign information can be queried and sign details between houses resource and customers can be comprehended.

Call records: be used to query call content of the customer and provide powerful help for employees to follow up the houses and customers.

Customer management flow is as Fig. 10

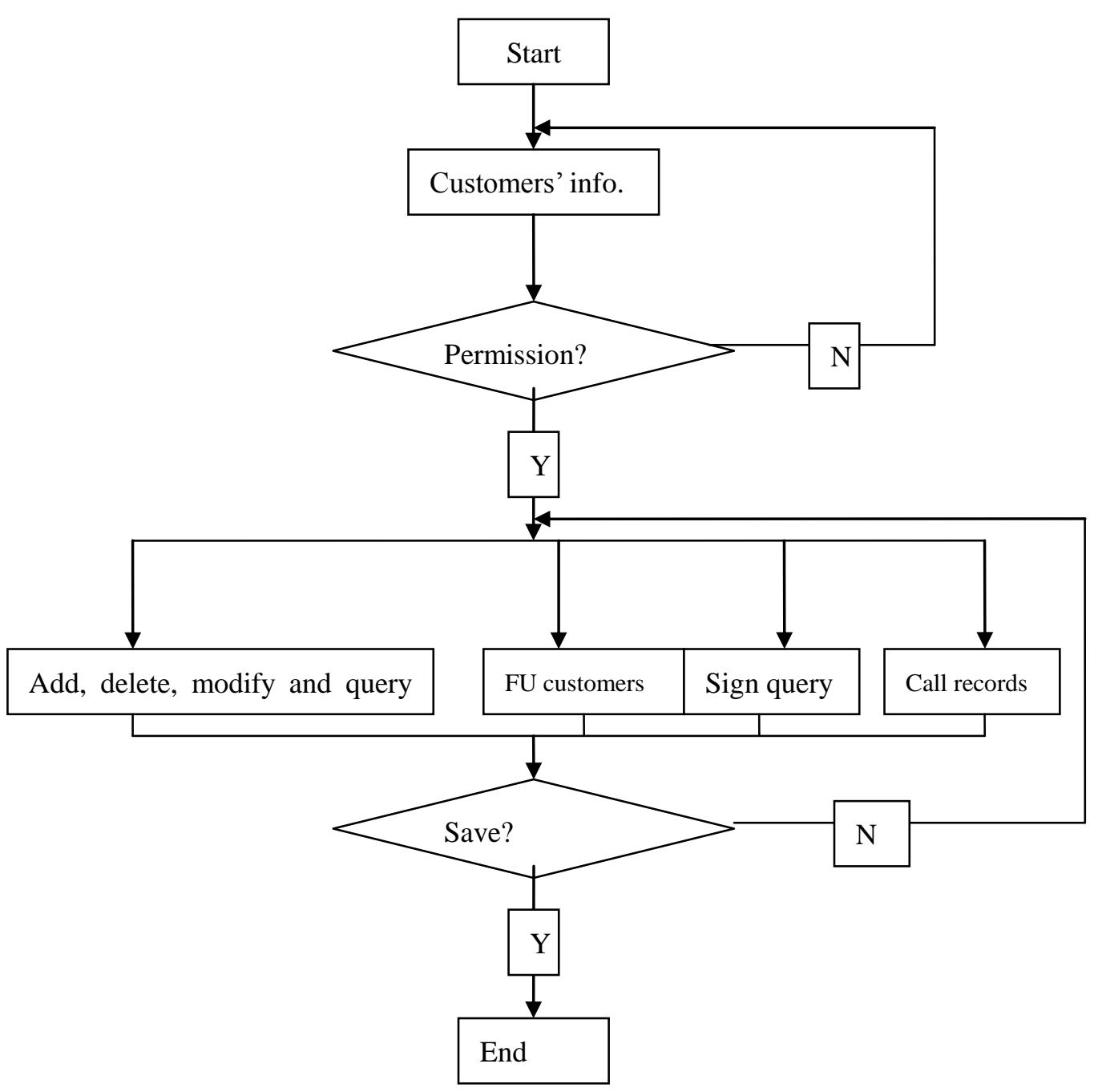

Fig. 10 Customer management flow

Internal statistics:

Customers and houses query: is mainly used to query the business level of the staff.

2. Comprehensive statistics: a lateral statistics according to housing, customers and employees.

3. Commission details: this data is from commission allocation from "property management" to "transaction management" in the signing.

4. Commission summary: is mainly the staff commission summary separately within a specified period.

System Settings

1. The company information setting: Here input the basic information of the company here, can display your company information in the poster. 
2. Staff management: can realize to add, modify, delete, and query the company employees as well as other functions.

3. Operation permissions Settings: Privilege group management is mainly used to add, modify, and delete permissions setting.

4. Change the current password: modify the current password.

5. Initialize data: here you can delete the specified data.

6. Parameter information Settings: Here you can add corresponding parameters according to your actual application.

7. System operation log: Here you can query to the data which has been modified, deleted and other operations detrimental to the original data.

The system Settings flow is as Fig. 11.

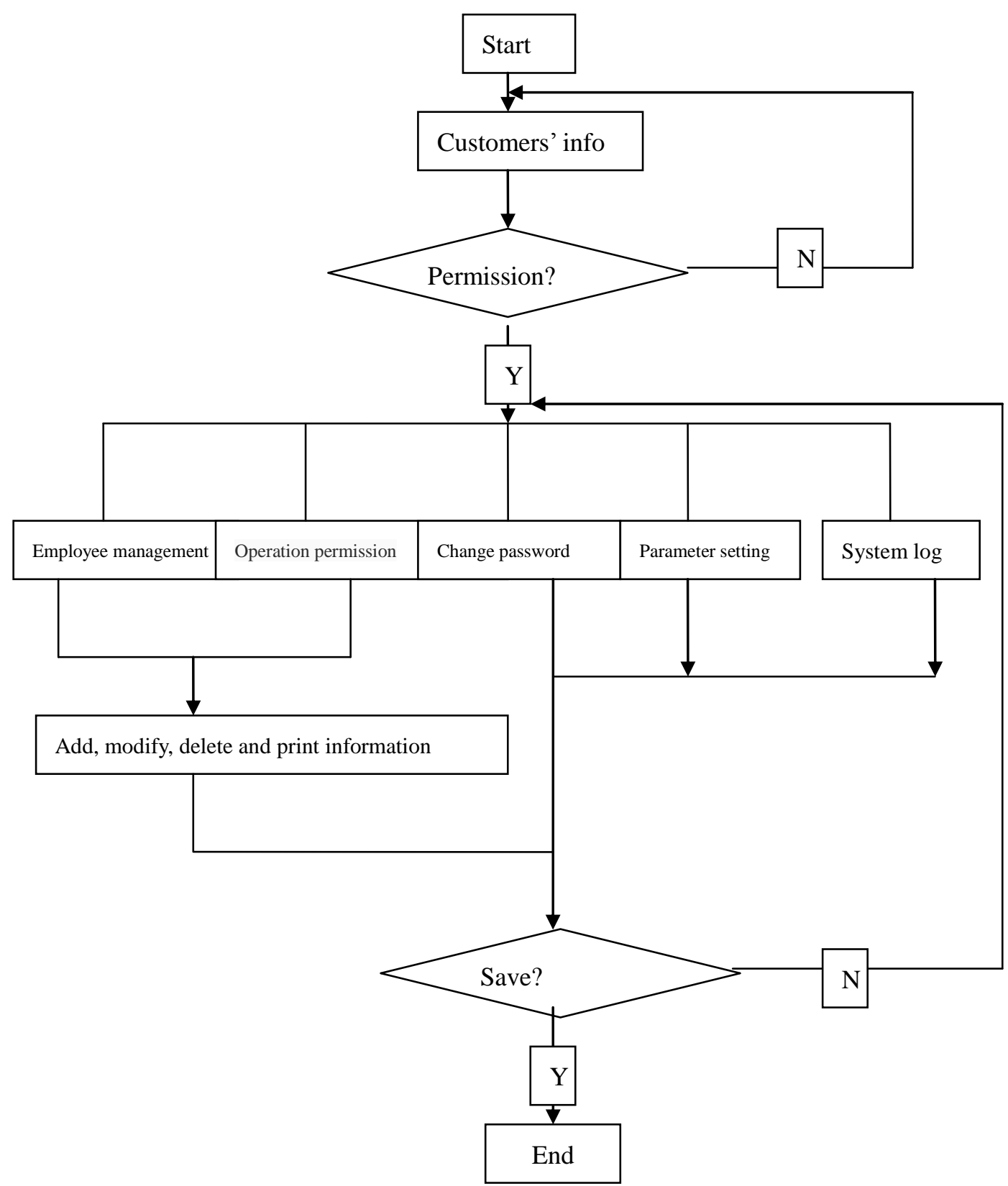

Fig. 11 The system Settings flow 
Data process design. Data process design is mainly manifested in processing direction and process of the information system in the entire system data. The main data flow of the system embodied in the data flow diagram. The system data flow is as Fig. 12.

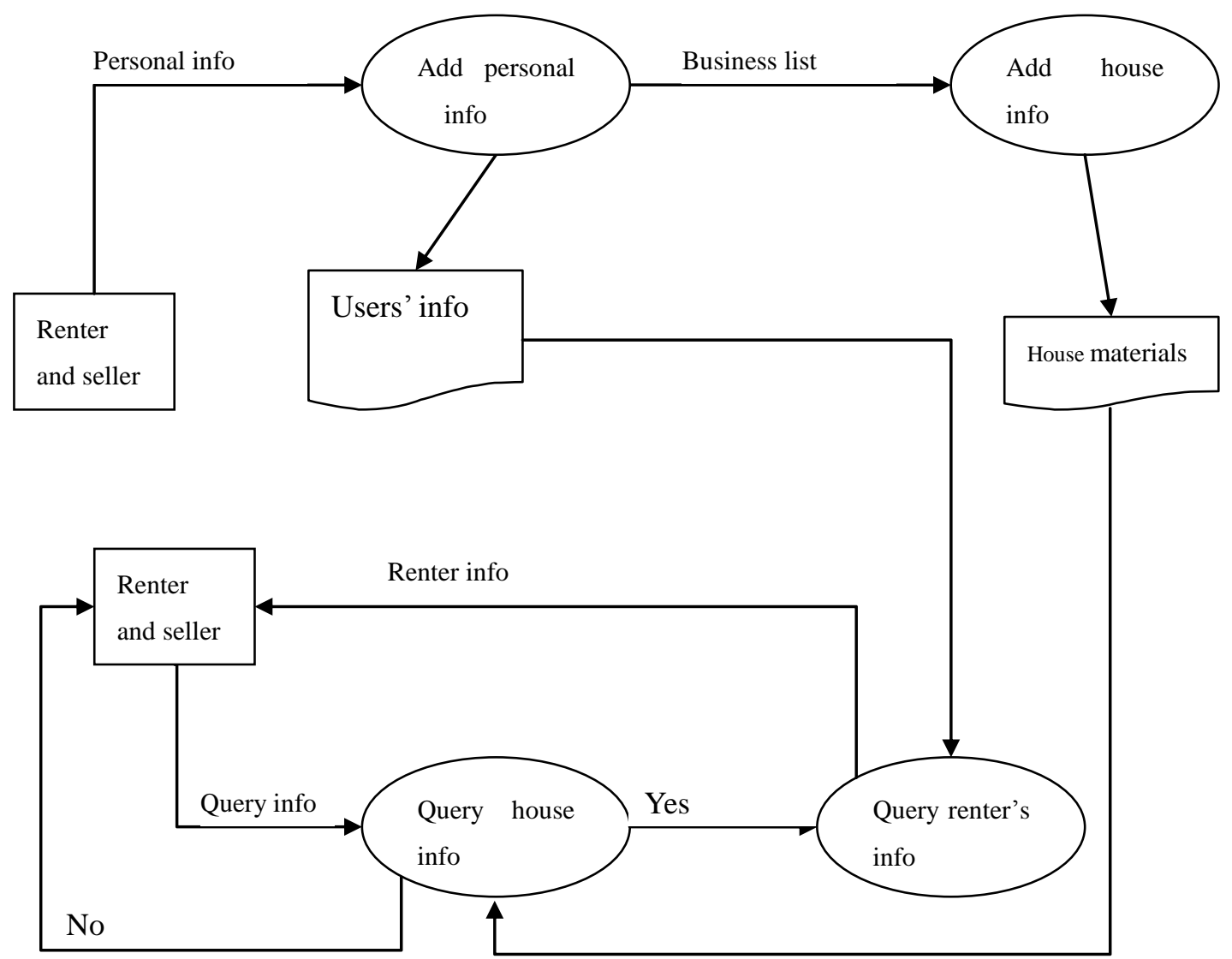

Fig. 12 The system data flow

Function and structure design of the system. The main task of function and structure design of the system is to describe the function modules the whole system can accomplish. The implementation function of the whole system function is clear in the function and structure system.

The function and structure of housing intermediary management system is as Fig. 13: 


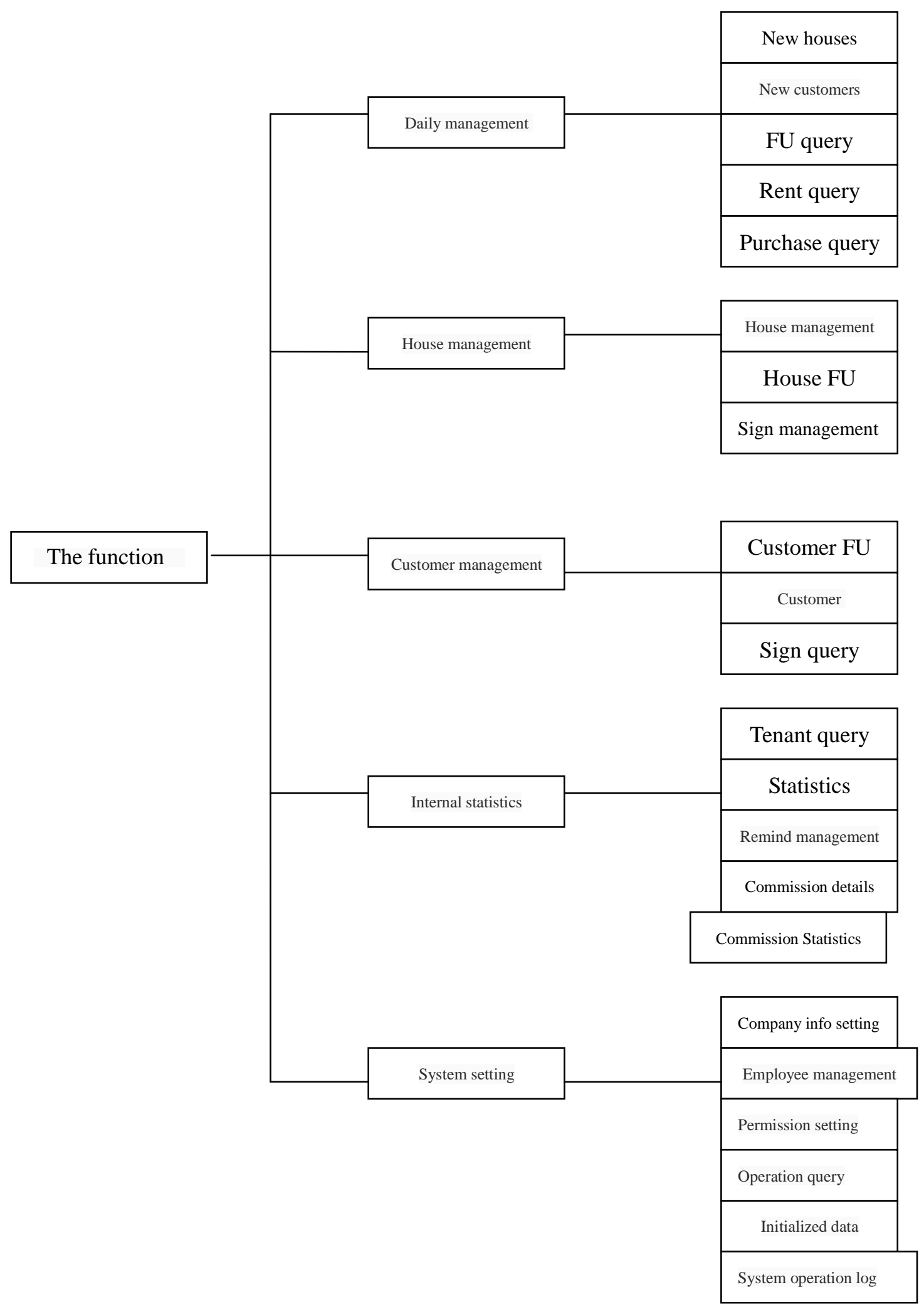

Fig. 13 The function and structure of system 


\section{Designs and implementation of function module}

Login modules of the system. According to the users' name and password, the system will query to all users' information in the database. Users cannot login without users' information. If there is the user's corresponding information that user is legitimate leading to a successful login. Meanwhile, the system will recognize user's identity; if it is a normal user, the window will switch to ordinary users' operating form; if it is a system administrator, the window will switch to administrator interface. Login modules of the system are as Fig. 14.

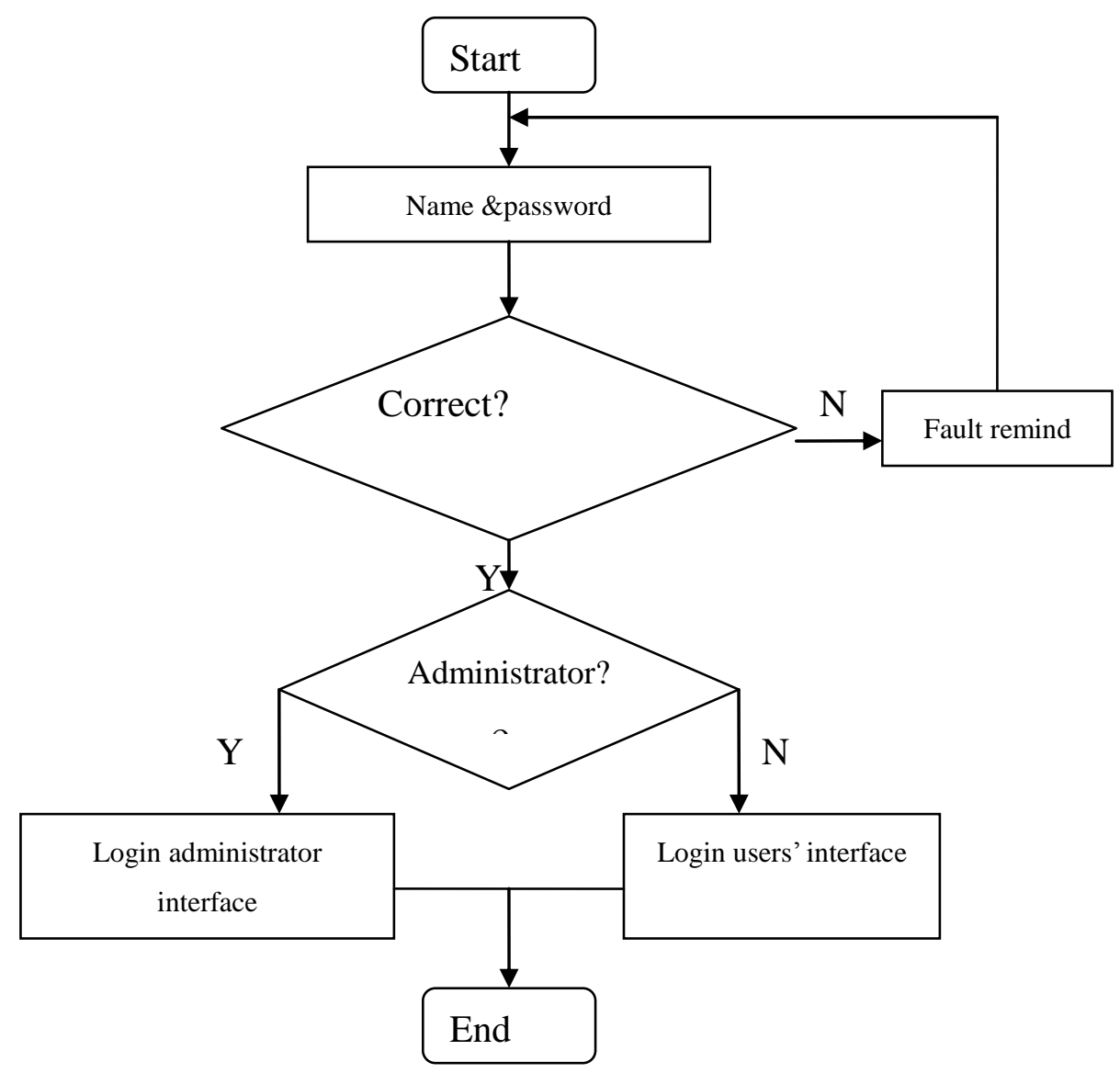

Fig. 14 Login modules of the system

New housing resources and housing resources' management module. New housing resources: Click on the "new housing" button in the main window; open the new housing resources window; register information according to the actual situation of the housing can complete the housing registration, which will be used in the software as query, modify, sign a contract and housing matching operation.

Customers' management module. Customer management: click on "customer management" - "customer management" button on the left side of the main window, open it and in this window customers' information can be added, modified, deleted, queried, exported, and printed, etc., Automatic matching between houses and customers also can be undertaken. The way to add a new customer is same as in the "daily management". Click on a customer in 
the customer management, and the matching houses will show up in "automatic matching the supply of homes" at the lower part of the window.

Customer information register flow is as Fig. 15.

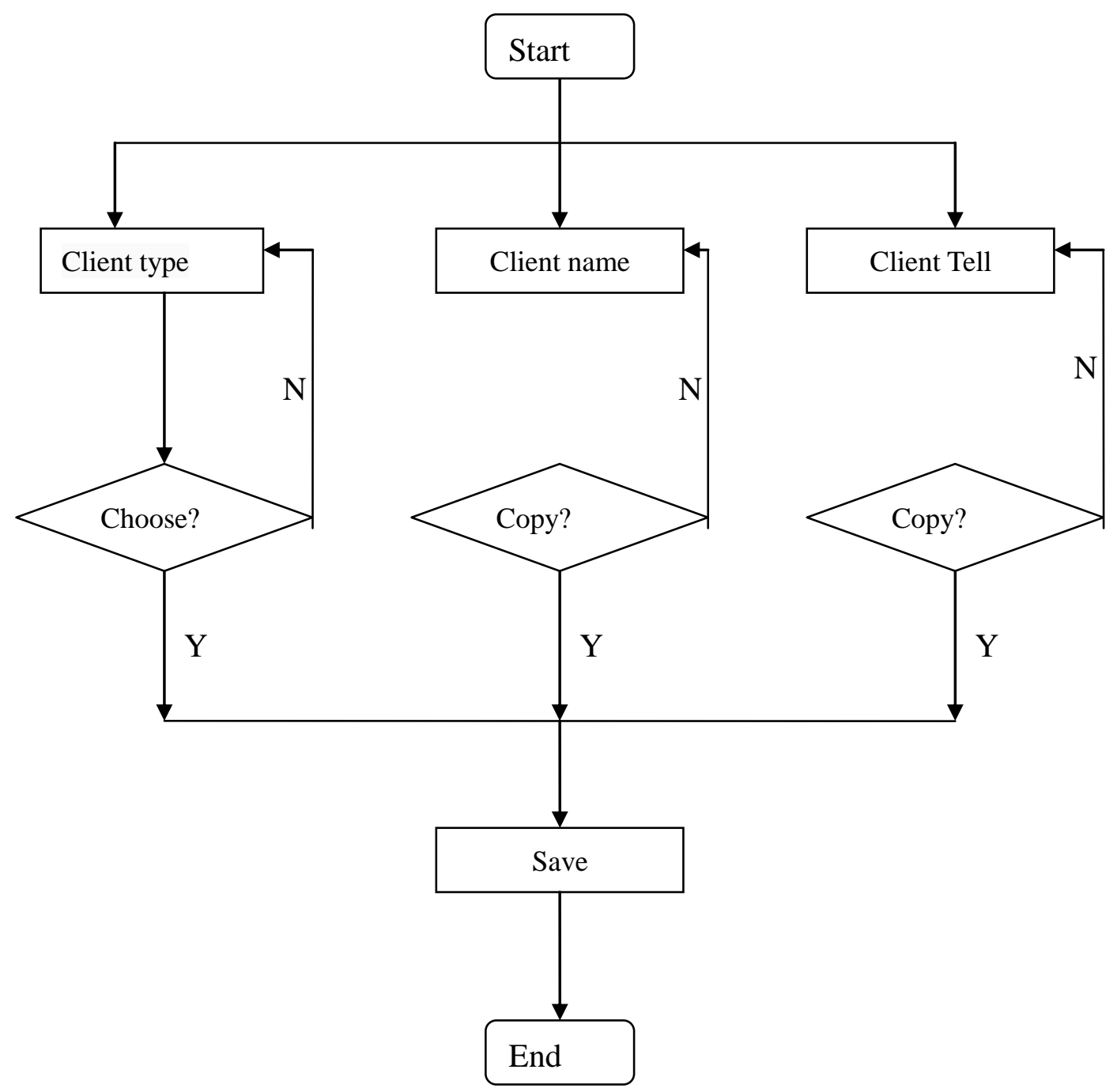

Fig. 15 Customer information register flow

Comprehensive statistics module. Comprehensive statistics: click on "internal statistics" "comprehensive statistics" button $t$ on the left side of the main window; open the comprehensive statistics window. This function is mainly a lateral statistics according to the housing resources, customers and employees, which intuitively reflects the comprehensive statistics of housing resources, customers and other properties, the number of customers, employees and other attributes, thus provides powerful message of business analysis and decision-making for the management.

\section{Conclusions}

The database technology is a technology of wide promising development. This design of the database software is an application of learnt knowledge, which contains modify, delete, add, query, printing of the database records. In this diploma project, the following experiences has been realized: analyze demand before starting any software system; In the whole program 
interface design, study and draw lessons from some successful examples, to make a friendly users' interface and completed function modules; the biggest challenges of Management system database design is how to design a reasonable, no redundant database, instead of guaranteeing the data consistency and integrity. Through the graduation design, I have learned a lot, and been familiar with the design process of studying a subject, design and experiment. At the same time, not only did I find information, but quickly find what I required in solving the problems encountered in the design.

\section{Acknowledgements}

This work was financially supported by project of Technology Department of Jiangxi Province [No 20143BBM26048] and the project of Technology Department of Jiangxi Province [No 2013BBE50051] also gives us lots of help.

\section{References}

[1]Luo,B. Visual C\# 2005 Classic Case of Database Development. Water Conservancy and Hydropower Press, 2009: 10 21

[2]Gao, M. Microsoft SQL Server 2005 Development Guide. Tsinghua University Press, 2009: 1 143

[3] (USA) Shari Lawrence Pfleeger. People's Posts and Telecommunications Publishing Press, 2010: 1 123

[4] Qi, L. Classic introduction of C\#, Tsinghua University press, 2010: 2 95

[5] Wang, X. Project Development Case Records of C \#. Tsinghua University Press, 2011: $5 \sim 10$

[6] (USA) Wood. SQL Server 2005 Classic Introduction to Database Management. Tsinghua University press, 2008: 4 90

[7] (USA) Martin. Agile Software Development - c \# - comments in English version. People's Posts and Telecommunications Publishing Press, 2008: 32 107

[8] Wang Jun. Actual Combat in 1200 Cases of C \# Development. Tsinghua University Press, 2011:12 76

[9] Shi, J. The Software Engineering Principle, Method and Application. Beijing: Mechanical Industry Publishing Press. 2008: 32 169

[10] Hector Garcia-Molina Jeffrey D.ULLman Jennifer WidomDatabase System Implementation. Wiley Publishing, 2007: 54 100 